Haya: The Saudi Journal of Life Sciences

Abbreviated Key Title: Haya Saudi J Life Sci ISSN 2415-623X (Print) |ISSN 2415-6221 (Online) Scholars Middle East Publishers, Dubai, United Arab Emirates Journal homepage: https://saudijournals.com/sjls

Original Research Article

\title{
Propofol Anaesthesia in Pregnant Red Sokoto Goats: An Assessment of Cardiopulmonary and Haematological Parameters
}

\author{
Abubakar Sadiq Yakubu ${ }^{1 *}$, Adamu Abdul Abubakar ${ }^{1}$, Olawale Alimi Alimi ${ }^{2}$, Abdulfatai Aremu ${ }^{3}$, Kabiru Hussaini ${ }^{4}$, \\ Abdullahi Teleh Elsa ${ }^{5}$, Keneth Idowu Onifade ${ }^{6}$, Raphael OC Kene ${ }^{1}$, John Bayo Adeyanju ${ }^{1}$ \\ ${ }^{1}$ Department of Veterinary Surgery and Radiology, Usmanu Danfodiyo University, Sokoto, Nigeria \\ ${ }^{2}$ Department of Veterinary Surgery and Radiology, University of Ilorin, No C2, Studiopedia, Off Ministry of Health, Fate Tanke Rd, behind Lgea \\ Primary School, Ilorin, Nigeria \\ ${ }^{3}$ Department of Veterinary Pharmacology and Toxicology, University of Ilorin, No C2, Studiopedia, Off Ministry of Health, Fate Tanke Rd, behind \\ Lgea Primary School, Ilorin, Nigeria \\ ${ }^{4}$ Ministry of Animal Health, Zamfara State, Nigeria \\ ${ }^{5}$ Department of Veterinary Surgery and Radiology, Federal University of Agriculture, Makurdi, Nigeria \\ ${ }^{6}$ Department of Veterinary Pharmacology and Toxicology, Usmanu Danfodiyo University, Sokoto, Nigeria
}

DOI: $10.36348 /$ sjls.2020.v05i04.003 $\quad$ | Received: 07.04.2020 | Accepted: 14.04 .2020 | Published: 29.04 .2020

*Corresponding author: Abubakar Sadiq Yakubu

Email: yakubu.abubakar@udusok.edu.ng

Mob: +2347038417775

\section{Abstract}

Despite the challenge, some complex surgical interventions will require a general anaesthesia which must be of rapid onset and recovery qualities to minimize the risks. Propofol, a phenolic compound meets the requirement of general anaesthetic agent in ruminants with its rapid onset and recovery properties and minimal effect on the vital and haematological parameters. Propofol has been used without adverse effects on cardiopulmonary and haematological parameters in pregnant goats. Like in other breeds of goat studied, we therefore hypothesized that propofol has no adverse effects or cardiopulmonary system and haematologic parameters and is safe for pregnant Red Sokoto goats. Five (5) healthy pregnant Red Sokoto does $(19 \pm 0.6 \mathrm{~kg})$ were acquired for the purpose of this study and stage of pregnancy was ascertained with the aid B-mode real time transcutaneous ultrasonography. After 14 days of acclimatization, propofol anaesthesia was induced at $4 \mathrm{mg} \mathrm{kg}^{-1}$ and maintained at $0.4 \mathrm{mgkg}^{-1} \mathrm{~min}^{-1}$ continuous infusion rate for 60 minutes. Vital parameters were taken using the standard procedures and blood samples were collected through a pre-placed intravenous catheter at pre-induction period ( 0 minute) to serve as the baseline and at 5, 10, 15, 30, 45, 60 and 120 minutes during anaesthesia. Statistical analysis showed no significant difference $(\mathrm{P}>0.05)$ for all the parameters measure except the respiratory rate, $\mathrm{MCV}$ and $\mathrm{MCH}$ that increased significantly $(\mathrm{P}<0.05)$ at the 120 minute period of observation. We therefore concluded that propofol is safe for anaesthesia in pregnant RSG with minimal to no effect on vital and haematological parameters.

Keywords: Red Sokoto goat, pregnant, propofol, vital parameters, cardiopulmonary.

Copyright @ 2020: This is an open-access article distributed under the terms of the Creative Commons Attribution license which permits unrestricted use, distribution, and reproduction in any medium for non-commercial use (NonCommercial, or CC-BY-NC) provided the original author and source are credited.

\section{INTRODUCTION}

Red Sokoto Goat (RSG) like any other breed of goat plays an important role in the food production system in Nigeria, contributes to the economy of the poor people by providing regular source of income and has the most outstanding characteristic of high quality hide and skin. Its high prolificacy and short gestation period make the animal suitable for production among poor and landless livestock farmers [1-3].

Goats undergo many surgical procedures, such as hernia, dystocia, management of traumatic injuries and they need a safe anaesthesia which could be achieved by same drugs used in other species [4]. Local infiltration and epidural anaesthesia supported by physical restraint are commonly carried out in ruminants for diagnostic, obstetrical and surgical procedures [5, 6]. Despite the challenges of general anaesthesia in ruminants, there are however situations whereby a non-cooperating patient is to be managed or complex diagnostic and surgical procedures like management of diaphragmatic hernia and orthopaedics, which will require a general anaesthesia for good prognosis [5, 7-10]. Vieitez et al., 2017 reported a craniotomy for the management of Coenurus cerebralis 
(gid), which cannot be ordinarily managed by physical restraint and local anaesthesia. In addition, some field anaesthesia, anaesthesia for magnetic resonance imaging and researches will require general anesthesia [11-13]. In recent time as well, goat has been preferred as an animal model in biomedical researchers, surgical training and teaching like in orthopaedics, cardiovascular, respiratory, reproductive and cerebrovascular studies [8, 14-16]. For ethical reasons therefore, appropriate anaesthetic and analgesic protocols are necessary in this species [11, 15] for complete unconsciousness, improved analgesia, good muscle relaxation, absence of all reflexes and loss of motor ability [5].

Total intravenous anaesthesia (TIVA) is not a common practice in goats, but now gaining a wider acceptance due to the dose-dependent cardiopulmonary depression of inhalant anaesthetic agents if considered for general anaesthesia [13] with lower risk of intraanaesthetic death [17]. TIVA has added advantage of stable intra-operative autonomic functions, smoother induction and recovery pollution of the working environment is averted [13]. If general anaesthesia is to be used in ruminants, it has to be of rapid onset with rapid recovery to prevent the high risk of regurgitation and tympany these species are predisposed to, hence the use of drug like propofol [18, 19].

Propofol (2,6-diisopropylphenol) is a phenolic compound, non-barbiturate, non-dissociative and noncummulative intravenous anaesthetic agent [20] with good quality anesthesia, rapid onset, short duration of action and rapid recovery, making the drug potentially useful in ruminants, in which these features are particularly desirable [7, 21-23]. Either administered as intermittent bolus or as continuous infusion, propofol has rapid metabolism and clearance rates in the body system [13, 16, 17]. These properties avert its dosedependent cardiopulmonary and vital organs depression $[13,19]$. It should however be combined with a potent analgesic drug as it does not proffer a substantial analgesia [2, 13]. Propofol could also proffer an antioxidant effect due to its phenolic chemical similarity to vitamin $\mathrm{E}$ by reacting with free radicals to generate phenoxy radicals $[24,25]$.

Successful use of propofol for induction and maintenance of anaesthesia in goats has been reported with relatively stable vital and haematological paramaters $[17,20,22,24,26,27]$. Choice of anaesthetic agent should be done with care pregnant small ruminants so as not to cause reduced placental blood flow and hypoventilation to the dam [28]. The use of propofol in pregnant animals has been reported without adverse effects on the maternal and foetal vital paramaters, uterine blood flow [29] or the spontaneous uterine contraction [30]. Propofol is therefore safer for pregnant animals as compared to other agents, though its less analgesic effect should be making up for [28].
Like in other breeds of goats across the world where the use of propofol has been documented in their pregnant does, we therefore carry out this study to know the cardiopulmonary and haemtological effects of propofol on pregnancy in RSG.

\section{MATERIALS AND METHODS}

Five (5) healthy pregnant Red Sokoto does $(19 \pm 0.6 \mathrm{~kg})$ were acquired for this research from a local market in Bodinga Local Government area of Sokoto State and transported to small ruminant pen of Faculty of Veterinary medicine of Usmanu Danfodiyo University, Sokoto. The acquisition was made such that their pregnancy was ascertained to be in second trimester using B-mode real time transcutaneous ultrasonography with $7.0 \mathrm{MHz}$ transcutaneous transducer as described by [31]. They were allowed to acclimatize for 14 days and fed with bean husk, wheat offal and hay twice daily while water was provided ad libitum.

Food and water were withdrawn 12 and 6 hours respectively prior to the period of induction of anaesthesia. To have access to the jugular veins, the left side of the neck was clipped around the jugular furrow. The skin was scrubbed using methylated spirit (La Onyz ${ }^{\circledR}$, Samstella Nigeria Limited, Abule Oba, Nigeria) and $18 \mathrm{G}$ intravenous catheters (Beromed GMBH Hospital Product, Berlin, Germany) were placed for the purpose of blood sampling and propofol administration as described by Correia, et al., 1996 and Adetunji, et al., 2002. The anaesthesia was induced with propofol $\left(\right.$ Pofol $^{\circledR}, 1 \%$ Dongkook Pharmaceuticals, Korea) at 4 $\mathrm{mgkg}^{-1}$ and maintained at $0.4 \mathrm{mgkg}^{-1} \mathrm{~min}^{-1}$ continuous infusion rate for 60 minutes $[34,35]$.

Blood sample was collected through the preplaced catheter before anesthetic induction to serve as the baseline and every 5 minutes for the first 15 minutes and at every 15 minutes afterward till the last 60th minute. The blood sample was also collected one hour after complete recovery. The blood samples collected were placed in a commercial ethylenediamine tetra acetic acid (EDTA) bottle (JRZ Plastilab, Beirut, Lebanon) and were analyzed for complete haemogram within 2 hours of collection full automatic blood cell counter (Erma PCE $210^{\circledR}$, Tokyo, Japan).

The base of the tail was clipped and scrubbed for the sensor of pulse oximeter. The heart rate (HR) and respiratory rate (RR) were measured using the pulse oximeter (PC-66 ${ }^{\circledR}$, Devon Medical Products, Jiangsu, China). While the temperature were measured using a digital thermometer per rectum. These were taken at the same time post-induction as stated for the blood sampling.

All the results generated were tabulated and presented as mean \pm SEM and statistical analysis was done using one-way ANOVA with repeated measure 
using GraphPad PRISM $5^{\odot}$ for Windows, Version 5.03, 2010. Level of significance was set at $\mathrm{P}<0.05$. The research was approved by the Faculty Animal Research and Ethical Committee.

\section{RESULT}

The induction was smooth without any obvious adverse effect on the pregnancy and the experimental animals. The onset was observed to be
$34.8 \pm 8.7$ seconds post-induction. The signs observed include minimal salivation, loss of jaw tone and pedal reflex and prolapse of the third eyelid. The records taken were presented in Figures 1-4 and Table-1.

There were no significant differences in all the parameters measured except the respiratory rate, $\mathrm{MCH}$ and $\mathrm{MCV}$, all at the $120^{\text {th }}$ minute.

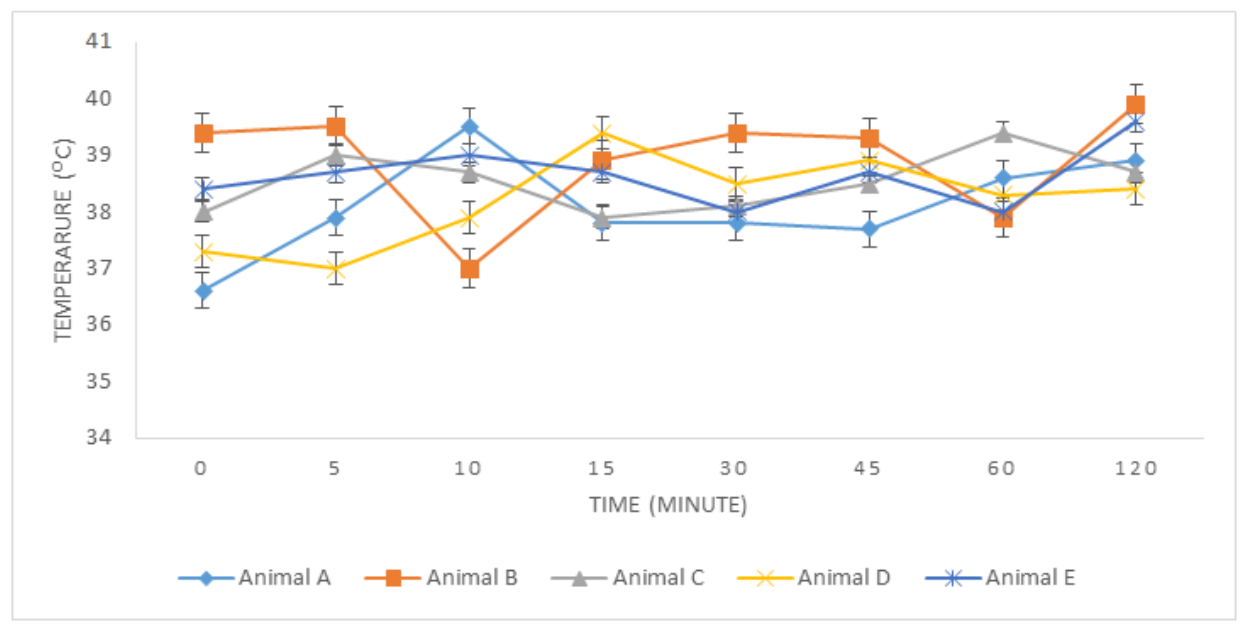

Fig-1: The temperature of the RSG (No significant difference was observed, $\mathbf{P}>0.05$ )

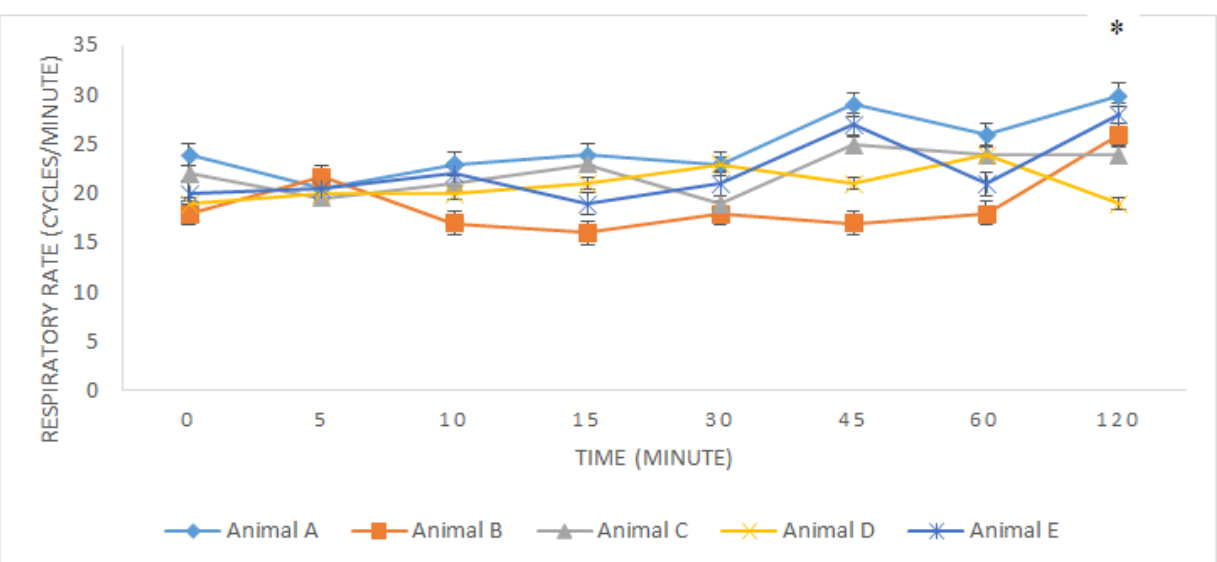

Fig-2: The respiratory rate of the RSG. Significant difference $(\mathrm{P}<0.05)$ was observed at the $\mathbf{1 2 0}^{\text {th }}$ minute when compared to the pre-induction period (baseline)

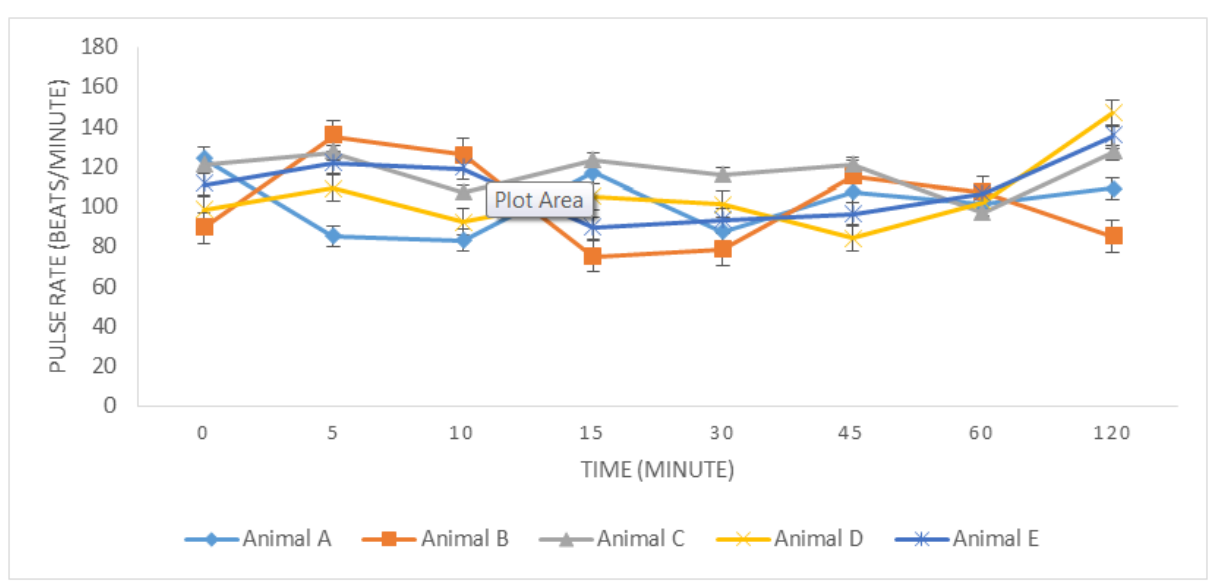

Fig-3: The pulse rate of the RSG. No significant difference $(\mathbf{P}>0.05)$ was observed 


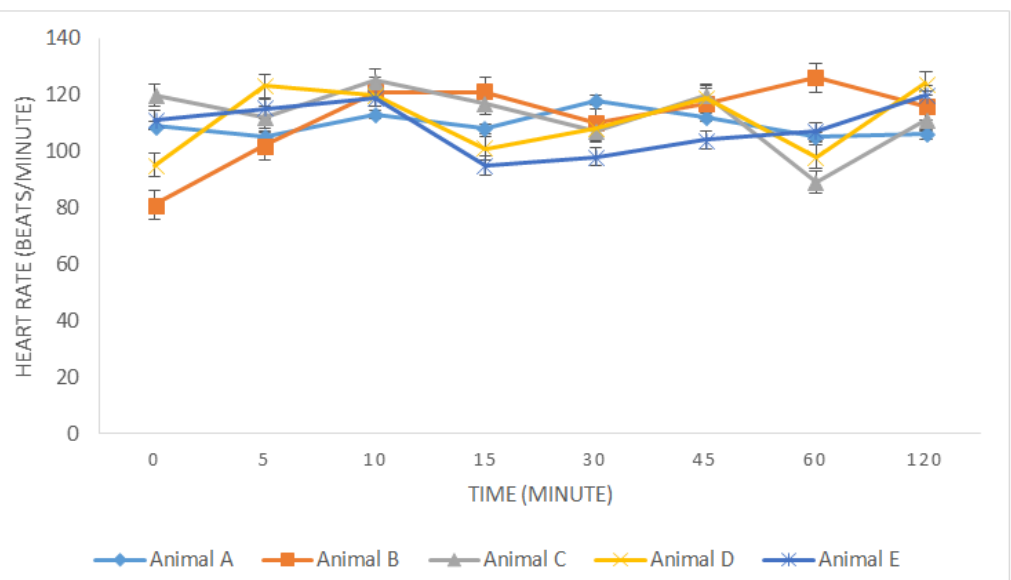

Fig-4: The heart rate of the RSG. No significant difference $(P>0.05)$ was observed

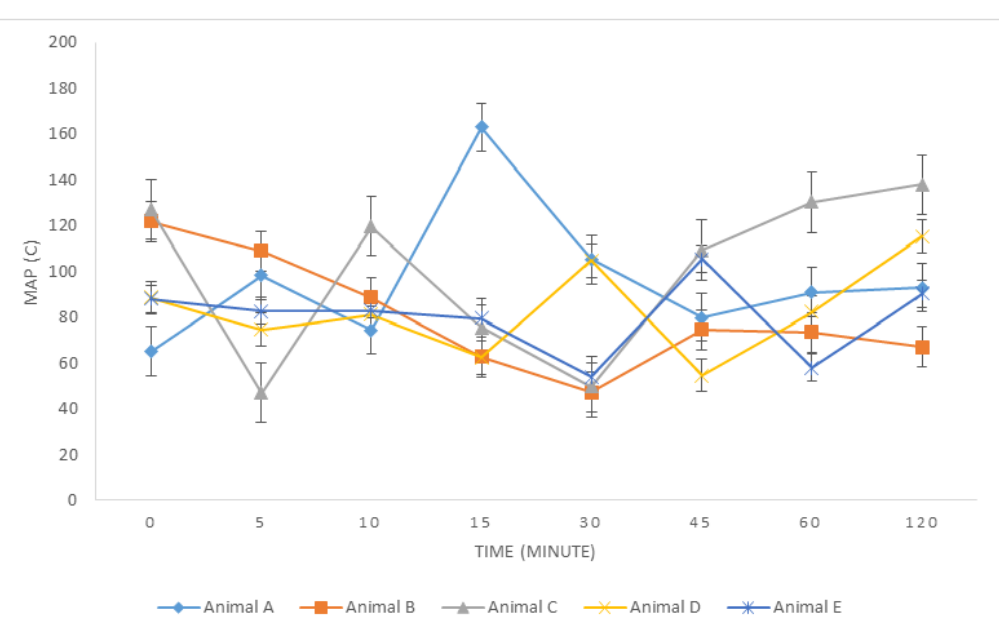

Fig-5: The MAP(C) of the RSG. No significant difference $(P>0.05)$ was observed

Table-1: The haematological parameters (Mean \pm SEM) of Red Sokoto does pre- and post-induction of anaesthesia $(\mathbf{n}=5)$

\begin{tabular}{|c|c|c|c|c|c|c|c|c|}
\hline & & \multicolumn{7}{|c|}{ Post-induction periods (minute) } \\
\hline & $\begin{array}{l}\text { Pre- } \\
\text { induction }\end{array}$ & 5 & 10 & 15 & 30 & 45 & 60 & 120 \\
\hline WBC X $10^{9} / \mathrm{L}$ & $54.08 \pm 2.45$ & $51.68 \pm 3.27$ & $51.8 \pm 3.08$ & $52.34 \pm 2.79$ & $52.76 \pm 2.49$ & $50.10 \pm 3.04$ & $51.46 \pm 2.45$ & $52.80 \pm 2.52$ \\
\hline GranX $10^{9} / \mathrm{L}$ & $15.68 \pm 1.27$ & $13.88 \pm 1.43$ & $\begin{array}{l}13.08 \pm \\
1.48\end{array}$ & $13.60 \pm 0.80$ & $12.94 \pm 1.73$ & $11.36 \pm 1.81$ & $10.88 \pm 1.93$ & $11.30 \pm 2.51$ \\
\hline $\operatorname{Lym} \times 10^{9} / \mathrm{L}$ & $31.74 \pm 1.65$ & $37.46 \pm 2.19$ & $\begin{array}{l}33.04 \pm \\
2.11\end{array}$ & $32.64 \pm 1.75$ & $33.28 \pm 2.55$ & $34.00 \pm 3.54$ & $34.06 \pm 3.39$ & $35.90 \pm 3.37$ \\
\hline Mono X $10^{9} / \mathrm{L}$ & $4.40 \pm 0.42$ & $4.12 \pm 0.39$ & $\begin{array}{l}3.68 \pm 0 \\
.47\end{array}$ & $4.08 \pm 0.17$ & $4.50 \pm 0.35$ & $3.42 \pm 0.44$ & $4.34 \pm 0.44$ & $5.04 \pm 1.16$ \\
\hline $\mathrm{RBC} X 10^{12} / \mathrm{L}$ & $11.62 \pm 0.23$ & $11.44 \pm 0.20$ & $11.18 \pm 0.27$ & $11.02 \pm 0.23$ & $11.20 \pm 0.18$ & $11.04 \pm 0.22$ & $11.50 \pm 0.26$ & $11.34 \pm 0.21$ \\
\hline HGB $(\mathrm{g} / \mathrm{dL})$ & $9.50 \pm 0.83$ & $8.80 \pm 0.74$ & $9.34 \pm 0.82$ & $9.24 \pm 1.00$ & $9.36 \pm 0.98$ & $8.92 \pm 0.98$ & $9.40 \pm 0.87$ & $9.26 \pm 0.96$ \\
\hline PCV $(\%)$ & $20.60 \pm 0.60$ & $18.80 \pm 1.16$ & $20.80 \pm 0.73$ & $20.80 \pm 0.58$ & $20.80 \pm 0.58$ & $20.80 \pm 0.58$ & $21.00 \pm 0.71$ & $20.20 \pm 0.58$ \\
\hline $\mathrm{MCV}(\mathrm{FL})$ & $16.68 \pm 0.53$ & $16.48 \pm 0.74$ & $16.48 \pm 0.74$ & $16.36 \pm 0.71$ & $16.64 \pm 0.57$ & $16.36 \pm 0.71$ & $15.54 \pm 1.28$ & $7.20 \pm 0.28^{\mathrm{a}}$ \\
\hline $\mathrm{MCH}$ & $7.04 \pm 0.13$ & $6.90 \pm 0.14$ & $7.02 \pm 0.18$ & $7.02 \pm 0.14$ & $7.02 \pm 0.18$ & $7.02 \pm 0.18$ & $7.06 \pm 0.21$ & $42.52 \pm 2.08^{a}$ \\
\hline
\end{tabular}

Means bearing different a superscript along the same row differ significantly from the pre-induction period $(\mathrm{P}<0.05)$. WBC: White blood cell count, Gran: Granulocyte, Lym: lymphocytes, Mono: Monocytes, RBC: Red blood cell count, HGB: Hemoglobin, PCV: packed cell volume, MCV: mean corpuscular volume, $\mathrm{MCH}$ : mean corpuscular hemoglobin

\section{DISCUSSION}

Certain complex surgical procedures like diaphragmatic herniorrhaphy, craniotomy, open reduction and internal fixation, tumour excision and many more will require general anaesthesia in ruminants $[7,5,8,10,13]$. Aside Caeseren section and other obstertics procedures like embryo transfer that could be carried out under general anaestheia [28], a pregnant goat can as well come down with any other condition that will require general anaesthesia like gid and diaphragmatic hernia. Therefore, the need to study a general anaesthetic drug like propofol that is known 
for rapid and smooth induction and recovery as required of a ruminant to reduce the risk of tympany and regurgitation $[18,19]$.

Propofol has been used successfully in many ruminants including goats $[17,20,22,24,26,27]$ and even in pregnant small ruminants [28-30] with stable vital and haematologic parameters. The safety of this agent is then studied in pregnant RSG at second trimester for subsequent usage when the need arises.

Smooth and rapid induction of anaesthesia (34.8 \pm 8.7 seconds) was observed in the present study similar to the observations of Dewangan et al., and Dzikiti et al., Salivation of small quantity was also observed as usual of general anaesthesia in ruminants [36].

The vital parameters measured were rectal temperature, respiratory, heart and pulse rates. All these parameters, except the respiratory rate, did not differ sginificantly when compared with the pre-induction (baseline) period through out the course of 120 minutes of observation. There respiratory rate however increased significantly $(25.40 \pm 1.89)$ when compared with the baseline $(20.60 \pm 1.08)$. Our findings of nonsignificant difference in the first 60 minutes of observation of the temperature was in accordance with the study of Kumar et al.(2014) on the clinicophysiological effect of propofol and dexmedetomidine in goats. Our observations on heart and respiratory rates differ probably due to dexmedetomidine premedication, an alpha-2 agonist which have profound effect on the cardiopulmonary system. Veronica et al., also reported a non-significant difference in the rectal temperature and heart rate while there was a significant difference observed in the respiratory rate, which was similar to our findings in the current study. This could be because the respiratory rate could easily increase due to ambient temperature, stress and handling. The values reported by Veronica et al., in their study were $108.0 \pm 12.5$ and $37.9 \pm 0.25$ as baseline for heart rate and rectal temperature respectively which were similar to our observation $(103.2 \pm 6.84$ and $37.94 \pm 0.48$ for heart rate and rectal temperature respectively), being the same breed, though different location.

This as well corroborate the fact that propofol did not have any deleterious effect on the vital parameters. The study of Setoyama et al., on pregnant Japanese Saanen goats using propofol as induction agent showed just significant increase in the heart rate in the first five minutes and later normalized while other parameters did not differ significantly. Breed responses to certain drugs and geographical location could be responsible for this difference. Some vital parameters that decreased after etorphine and azaperone premedication were normalized upon administration of propofol [37].
Dzkiti et al., and Madan, et al., also used propofol to induce anaesthesia in Boer and Indian local goats respectively and observed no significant changes. Bodh et al., also found out that the vital parameters were maintained in buffalo with propofol anesthesia as compared to thiopentone, which also have the deleterious effect on the foetus after crossing the placenta-blood barrier. In the anaesthetic induction study using buprenorphine-propofol in atropinized goats, Dewangan et al., reported a significant decrease in the heart and respiratory rates while the rectal temperature did not differ significantly when compared with the baseline values. The report on the rectal temperature is similar to our study while the difference in the heart and respiratory rates could be as a result of buprenorphine that was co-administered. Okwudili et $a l$., also pre-medicated with xylazine before propofol induction in West African Dwarf and observed a decreased vital parameter.

In craniotomy surgery in a goat under propofol TIVA, Vieitez et al., reported a stable MAP. In addition, Khattri et al., reported a significant decrease in MAP over a period of 75 minutes in uraemic buffalo calves induced with propofol which is in discordance with the findings in the study. The researchers however pre-medicated with dexmedetomidine, which could have caused the decrease observed. In cats, IIkiw and Pascoe, observed a higher MAP in propofol administration as compared to that of isoflurane. This agreed with our findings of non-deletorious effect of propofol on MAP.

Propofol being an ultra-short acting agent has rapid distribution and elimination after bolus injection or constant infusion without cumulative effect [17] and therefore may not have profound haematological effect of blood. Omar et al., observed no significant difference in the value of PCV, $\mathrm{Hgb}, \mathrm{WBC}, \mathrm{RBC}, \mathrm{MCH}$ and $\mathrm{MCV}$ when propofol anesthesia was compared with ketamine and thiopental in Baghdad local breed of goat in 60 minute observation period as observed in the current study. But there was however, a significant increase in the $\mathrm{MCH}$ and $\mathrm{MCV}$ at 120 minute of observation. Kumar et al., however reported a decreased $\mathrm{Hb}$, PCV and $\mathrm{WBC}$ as opposed to the current study. The discrepancy could be as a result of medetomidine premedicant which has the potential of pooling the circulating blood cells into the spleen and other reservoirs [17, 40] and the on-going haemorrhage in urolithiasis in the goats observed [17]. The differential white blood count did not differ significantly in the study of Kumar et al., as observed in our study. In agreement with the findings of the current study, Dewangan et al., reported in Indian goats using propofol anaesthesia, non-significant difference in $\mathrm{Hb}$, PCV and total WBC. The non-significant difference in the current study is suggestive of the fact that propofol has minimal effect on haematology. 


\section{CONCLUSION}

From the current research and earlier findings, it has been observed that without doubt that propofol anaesthesia has minimal effects on both vital and haematological parameters in pregnant RSG. Therefore, propofol can be used in all clinical condition requiring general anaesthesia in pregnant RSG be it obstetrics or other conditions that are to be managed by surgical intervention.

Conflict of Interest: The authors declare no conflict of interest.

\section{REFERENCES}

1. Jensen, C., \& Van den Burg, K. (2004). Goat keeping in the tropics. CTA (Technical Center for agriculture and rural co-operation) Macmillian Education limited.

2. Dewangan, R., Maravi, M., Tiwari, S., \& Sharda, R. (2020). Alternations on haemato-biochemical profiles following administration of atropinebuprenorphine-propofol anaesthesia in goats. International Journal of Chemical Studies, 8(1), 1136-1139. https://doi.org/10.22271/chemi.2020.v8.i1o.8402

3. FAO. (2009). Food and Agriculture Organization of the United Nation Repository Publication on the Statistic of domestic goats in Africa.

4. Dewangan, R., Maravi, M. S., Tiwari, S. K., Kalim, M. O., \& Sharda, R. (2019). Effect on Clinico-Physiological Parameters after Administration of Buprenorphine-Propofol Anaesthesia in Atropinized Goats. International Journal of Current Microbiology and Applied Sciences, 8(4), 2382-2388.

5. Khattri, S., Kinjavdekar, P., Aithal, H. P., Pawde, A. M., \& Kumar, R. (2013). Dexmedetomidine with Butorphanol and Propofol for Total Intravenous Anaesthesia in Uraemic Buffalo Calves. Advances in Animal and Veterinary Sciences, 1(2S), 15-23.

6. Kayode, O. A. (2017). Studies on Epidural anaesthesia using lidocaine with Adrenaline on Hemato-biochemical responses in pregnant West African Dwarf goats. E3 Journal of Medical Research, 6(2), 012-015. https://doi.org/10.18685/EJMR(6)2_EJMR-17-012

7. Brohi, R. D., Kalhoro, A. B., Kachiwal, A. B., Kalhoro, I. B., Kalhoro, D. H., Ahmed, S., \& Bhattaria, D. (2019). Comparative Effect of Propofol and Thiopentone Sodium in Sheep Sedated with Xylazine Hydrochloride. Pakistan Journal of Zoology, 51(1), 1-7.

8. Omar, R. A., Aziz, O. K., \& Majeed, A. A. (2016). Effect of three general anesthetic protocols on hematological parameters in goats. 3rd Scientific Conference - College of Veterinary Medicine University of Tikrit, 2-3 May 2016, (May), 18-23. Tikrit, Iraq.

9. Vieitez, V., Álvarez Gómez de Segura, I., López
Rámis, V., Santella, M., \& Ezquerra, L. J. (2017). Total intravenous anaesthesia in a goat undergoing craniectomy. BMC Veterinary Research, 13(1), 287. https://doi.org/10.1186/s12917-017-1205-2

10. Muchalambe, B., Dilipkumar, D., Shivaprakash, B. V, Venkatgiri, \& Patil, M. (2018). Clinical and physiological evaluation of midazolam- propofol and xylazine-propofol induction combination for isoflurane anaesthesia in cattle. The Pharma Innovation, 7(8), 8-11.

11. Carroll, G. L., Hartsfield, S. M. \& Hambleton, R. (1997). Anesthetic effects of tiletamine zolazepam, alone or in combination with butorphanol, in goats. Journal of the American Veterinary Medical Association, 211, 593-597. PMID:9290827

12. Larenza, M. P., Bergadano, A., Iff, I., Doherr, M. G., \& Schatzmann, U. (2005). Comparison of the cardiopulmonary effects of anaesthesia maintained by continuous infusion of ketamine and propofol with anaesthesia maintained by inhalation of sevoflurane in goats undergoing magnetic resonance imaging. America Journal of Veterinary Research, 66(12), 2135-2141. http://dx.doi.org/10.2460/ajvr.2005.66.2135

13. Dzikiti, T. B. (2013). Intravenous anaesthesia in goats: A review. Journal of South African Veterinary Association, 84(1), 1-8. https://doi.org/10.4102/jsava.v84i1.499

14. Carroll, G. L., Hooper, R. N., Slater, M. R., Hartsfield, S. M., \& Matthews, N. S. (1998). Detomidine-butorphanol-propofol for carotid artery translocation and castration or ovariectomy in goats. Vet Surg; 27: 75-82.

15. Kästner, S. B. R., Von Rechenberg, B., Keller, K., \& Bettschart-Wolfensberger, R. (2001). Comparison of Medetomidine and Dexmedetomidine as Premedication in Isoflurane Anaesthesia for Orthopaedic Surgery in Kästner Sheep. Journal of Veterinary Medicine Series A: Physiology Pathology Clinical Medicine, 48(4), 231-241. https://doi.org/10.1046/j.14390442.2001.00354.x

16. Kumandaş, A., \& Elma, E. (2015). Comparison of sevoflurane and isoflurane effects on cardiovascular andrespiratory system during spontaneous ventilation in Angora goats. Turkish Journal of Veterinary and Animal Sciences, 39, 501-506. https://doi.org/10.3906/vet-1501-75

17. Kumar, R., Amarpal, K. P., Hp, A., Am, P., Kumar A, Singh J, ... Madhu. (2014). Clinicophysiological, haematobiochemical and haemodynamic effect of propofol and ketamine with dexmedetomidine in urolithic goats. Veterinary World, 7(8), 566-573. https://doi.org/10.14202/vetworld.2014

18. Bodh, D., Singh, K., Mohindroo, J., Mahajan, S. K., Anand, A., \& Saini, N. S. (2013). Propofol and thiopentone sodium as induction agents in water buffaloes (Bubalus bubalis): A comparative study. 
Journal of Applied Animal Research, 41(3), 370373.

https://doi.org/10.1080/09712119.2013.782867

19. Sharma, A. (2010). Propofol in Veterinary Practice - A Review. Retrieved March 28, 2020, from Priory Lodge Education website: http://www.priory.com/vet/propofol.htm

20. Hall, L. W., Clarke, K. W., \& Trim, C. M. (2001). Anaesthesia of sheep, goats and other herbivores. In: Veterinary anaesthesia. 10th edition. London: WB Saunders. p. 341-66

21. Ewing, K. K. (1990). Anesthesia Techniques in Sheep and Goats. Veterinary Clinics of North America: Food Animal Practice, 6(3), 759-778. https://doi.org/10.1016/S0749-0720(15)30845-8

22. Prassinos, N. N., Galatos, A. D., \& Raptopoulos, D. (2005). A comparison of propofol, thiopental or ketamine as induction agents in goats. Veterinary Anaesthesia and Analgesia, 32(5): 289-296.

23. Dzikiti, T. B., Stegmann, G. F., Hellebrekers, L. J., Auer, R. E. J., \& Dzikiti, L. N. (2009). Sedative and cardiopulmonary effects of acepromazine, midazolam, butorphanol, acepromazinebutorphanol and midazolam-butorphanol on propofol anaesthesia in goats. Journal of South African Veterinary Association, 80(1), 10-16.

24. Veronica, I. O., Ayo, J. O., \& Aluwong, T. (2017). Modulatory Effect of Ascorbic Acid on PropofolInduced Anaesthesia in Goats. Journal of Anesthesiology, 5(3), 19. https://doi.org/10.11648/j.ja.20170503.11

25. Gokalp, E., Gurgoze, S., \& Altan, S. (2020). Effects of xylazine-ketamine, xylazine-propofol and xylazine-ketamine-propofol administration on free radical generation and blood gases in sheep. Indian Journal of Animal Research, 54(2), 148154. https://doi.org/10.18805/ijar.B-977

26. Pablo, L. S., Bailey, J. E., \& Ko, J. C. H. (1997). Median effective dose of propofol required for induction of anaesthesia in goats. $\mathrm{J} \mathrm{Am} \mathrm{Vet} \mathrm{Med}$ Assoc, 211(1): 86-88.

27. Okwudili, U. C., Athanasius, E. C., \& Ijeoma, U. R. (2014). Assessment of Common Anaesthetic and Clinical Indices of Multimodal Therapy of Propofol, Xylazine, and Ketamine in Total Intravenous Anaesthesia in West African Dwarf Goat. Journal of Veterinary Medicine, 2014, 1-6. https://doi.org/10.1155/2014/962560

28. Setoyama, K., Shinzato, T., Misumi, K., Fujiki, M., \& Sakamoto, H. (2003). Effects of PropofolSevoflurane Anesthesia on the Maternal and Fetal Hemodynamics Blood Gases, and Uterine Activity in Pregnant Goats. Journal of Veterinary Medical Science, 65(10), 1075-1081.

29. Gaynor, J. S., Wertz, E. M., Alvis, M., \& Turner, A. S. (1998). A comparison of the haemodynamic effects of propofol and isoflurane in pregnant ewes. J. Vet. Pharmacol. Ther. 21(1): 69- 73. https://doi.org/10.1046/j.1365-2885.1998.00110.x
30. Karsli, B., Kaya, T. and Cetin, A. (1999). Effects of intravenous anesthetic agents on pregnant myometrium. Pol. J. Pharmacol. 51(6): 505-510.

31. Abdelghafar, R. M., Bakheit, A. O., \& Ahmed, B. H. (2007). B-Model Real-Time Ultrasonography for Pregnancy Diagnosis and Fetal Number in Saanen Goats. J. Anim. Vet. Adv., 6(5):702-705.

32. Correia D., Nolan, A. M., \& Reid, J. (1996). Pharmacokinetics of Propofol Infusions, either Alone or with Ketamine in Sheep Premedicated with Acepromazine. Res. Vet. Sci. 60: 213-217

33. Adetunji, A., Ajadi, R. Adewoye C. O., \& Oyemakinde, B. O. (2002). Total intravenous anaesthesia with propofol: repeat bolus versus continuous propofol infusion technique in Xylazine pre-medicated dogs, Israel Journal of Veterinary Medicine, 57(4): 139-144.

34. Kaiser-Klingler, S. (2012) https://www.acvs.org/files/proceedings/2012/data/ papers/170.pdf. Access online 15/01/2019

35. Ferreira J. P., Ndawana, P. S., Dzikiti, L. N., \& Dzikiti, B. T. (2016). Determination of the minimum infusion rate of propofol required to prevent purposeful movement of the extremities in response to a standardized noxious stimulus in goats. Veterinary Anaesthesia and Analgesia, 43(5), 519-527. https://doi.org/10.1111/vaa.12327

36. Galatos, A. D. (2011). Anesthesia and Analgesia in Sheep and Goats. Veterinary Clinics of NA: Food Animal Practice, 27(1), 47-59. https://doi.org/10.1016/j.cvfa.2010.10.007

37. Izwan, A., Snelling, E. P., Seymour, R. S., Meyer, L. C. R., Fuller, A., Haw, A., \& Maloney, S. K. (2018). Ameliorating the adverse cardiorespiratory effects of chemical immobilization by inducing general anaesthesia in sheep and goats: implications for physiological studies of large wild mammals. Journal of Comparative Physiology B: Biochemical, Systemic, and Environmental Physiology, 188(6), 991-1003. https://doi.org/10.1007/s00360-018-1184-z

38. Madan, A. K., Korde, J. P., Das, A. K., \& Rastogi, S. K. (2010). Propofol-induced electroencephalographic, electrocardiographic and spirometric changes in goats. Veterinarski Arhiv, 80(1), 27-39.

39. Ilkiw, J. E., \& Pascoe, P. J. (2003). Cardiovascular effects of propofol alone and in combination with ketamine for total intravenous anesthesia in cats. American Journal of Veterinary Research, 64(7), 913-917. Retrieved from http://www.ncbi.nlm.nih.gov/pubmed/12856778

40. Umar, M., \& Wakil, Y. (2013). Effects of the combination of ketamine and medetomidine anaesthesia on haematological parameters in Sahel goats. Sokoto Journal of Veterinary Sciences, $11(1)$, 66-69. 